\title{
Linking root traits and competitive success in grassland species
}

\author{
Janneke M. Ravenek • Liesje Mommer • Eric J. W. Visser • Jasper van Ruijven • \\ Jan Willem van der Paauw • Annemiek Smit-Tiekstra • Hannie de Caluwe • \\ Hans de Kroon
}

Received: 29 November 2015 / Accepted: 22 February 2016/Published online: 5 March 2016

(C) The Author(s) 2016. This article is published with open access at Springerlink.com

\begin{abstract}
Background and aims Competition is an important force shaping plant communities. Here we test the hypothesis that high overall root length density and selective root placement in nutrient patches, as two alternative strategies, confer competitive advantage in species mixtures.

Methods We performed a full-factorial pairwise competition experiment with eight grassland species in soil with homogeneously distributed nutrients, or with nutrients concentrated in a single patch. We measured species-specific relative growth rate, root length density, selective root placement, and ion uptake rates of all species in monocultures and in mixtures.

Results Grasses showed higher specific root length overall and forbs a higher selective root placement in the nutrient patch. However, relative growth rate and root length density were more strongly related to
\end{abstract}

Responsible Editor: Duncan D. Cameron .

Electronic supplementary material The online version of this article (doi:10.1007/s11104-016-2843-z) contains supplementary material, which is available to authorized users.

J. M. Ravenek • E. J. W. Visser · J. W. van der Paauw • A. Smit-Tiekstra $\cdot H$. de Caluwe $\cdot H$. de Kroon $(\bowtie)$ Institute for Water and Wetland Research, Department of Experimental Plant Ecology, Radboud University Nijmegen, PO Box 9100, 6500 GL Nijmegen, The Netherlands e-mail: h.dekroon@science.ru.nl

L. Mommer · J. van Ruijven · J. W. van der Paauw Plant Ecology and Nature Conservation Group, Wageningen University, PO Box 47, 6700 AA Wageningen, The Netherlands competitive ability (measured as relative yield per plant), with little distinction between grasses and forbs. Conclusions Our results suggest that short-term competitive success was related to fast growth and high root densities, irrespective of nutrient heterogeneity. Developing a large root mass quickly may overwhelm the importance of other traits in the establishment phase of plants, although these other traits may prove to be important in the long run.

Keywords Soil nutrientheterogeneity Nutrient uptake . Root length density $\cdot$ Relative growth rate $\cdot$ Specific root length $\cdot$ Selective root placement

\section{Introduction}

Functional traits of plants are increasingly incorporated in analyses of ecosystem functioning, such as plant productivity (Bardgett et al. 2014; Díaz et al. 2007; Reich 2014; Violle et al. 2007). Initially, most research focused on aboveground traits, but belowground traits are receiving increased recognition (Reich 2014). A growing body of research is linking root traits to the resource economics spectrum, distinguishing acquisitive fast-growing plant species from conservative slow-growing plant species (Comas and Eissenstat 2009; Fort et al. 2012; McCormack et al. 2012; Reich 2014; Roumet et al. 2006). Local competitive interactions are also hypothesised to be driven by plant traits. Again, the focus often is on aboveground traits and root traits have been little studied, except for selective root 
placement (SRP), the ability of plant roots to preferentially forage in nutrient hotspots (Cahill Jr and McNickle 2011, de Kroon et al. 2003, Hodge 2004).

Selective root placement enables the plant to take up nutrients where the largest profit is to be expected and can be advantageous for performance under heterogeneous nutrient distributions (Cahill $\mathrm{Jr}$ and McNickle 2011; Fransen et al. 2001; Hodge 2004; Hodge et al. 1999; Robinson et al. 1999; Shemesh et al. 2010). For example, Fransen et al. (2001) showed that species with the highest SRP gained competitive advantage when nutrients were heterogeneously distributed in soil. However, several other studies have shown that species with the ability to selectively place roots in monoculture, do not always gain competitive advantage in mixtures (Bliss et al. 2002; Cahill and Casper 1999; Mommer et al. 2011; Rajaniemi 2007). Moreover, as recently shown, the degree of SRP expressed in interspecific competition is not necessarily the same as in individually grown plants (McNickle et al. 2015). This suggests that SRP is but one strategy that affects competitive interactions. Indeed, the production of an overall high root length density (RLD) has been suggested as a successful strategy for local competition for nutrients, particularly if these roots are cheap in terms of carbon investment (i.e. high specific root length (SRL); Hodge 2004) and are capable of high nutrient uptake rates per unit root length (Fransen et al. 1999; Mommer et al. 2011). For example, (Mommer et al. 2011) showed, in an experiment with two grass species, that the species that produced the highest RLD overall, was more successful in competition in heterogeneous soils by taking up more nutrients than the species that selectively placed its roots in nutrient hotspots. Hence, plant species may display different strategies that may confer similar competitive advantages: SRP or high overall RLD.

Root traits are to some degree phylogenetically dependent (Cadotte et al. 2009; Kembel and Cahill 2005; Schroeder-Georgi et al. 2016). Grasses generally have a higher SRL (Leuschner et al. 2013), potentially achieving a higher RLD per biomass investment. Herbaceous species often show a stronger SRP response to nutrient patches than grasses (Farley and Fitter 1999; Kembel et al. 2008; Mommer et al. 2012), but interspecific variation within groups is high (Roumet et al. 2006).

This brief overview underscores the current lack of consensus about what root traits confer advantage in competition. In most previous work, both the number of species investigated and the variety of traits measured was limited. Here, we aim to identify root traits that determine competitive success in pairwise competition for a set of eight grassland species. Species-specific root biomass in interspecific species pairs was determined, using molecular techniques (Mommer et al. 2008, 2010). This allows us to directly examine belowground plant performance in competition. We determined RLD, SRL, and root ion uptake activity (approximated by tracer element uptake) in monocultures under homogeneous and heterogeneous distribution of nutrients in the soil. We ask the following questions (see also Fig. 1a):

1. Do phylogenetic groups, i.e. grasses and forbs, differ in root traits? We expect grasses to have higher SRL and RLD as well as higher nutrient uptake rates than forbs, and forbs to show higher SRP in heterogeneous soil.
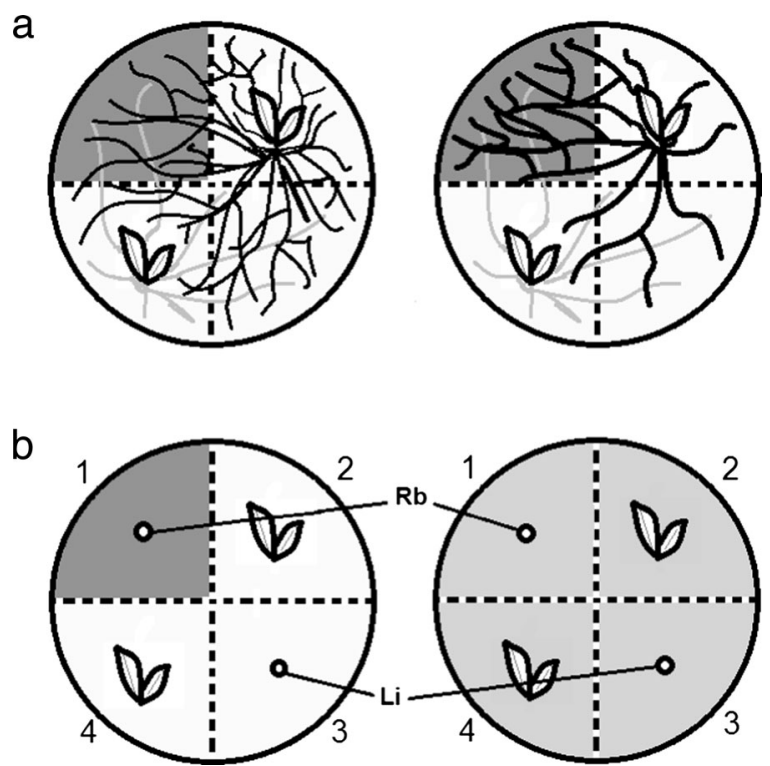

Fig. 1 a) Visual representation of two possible strategies of nutrient acquisition, and b) the experimental set-up of the experiment to test these strategies. a) The first strategy is a combination of high overall root length density (RLD) and high ion / nutrient uptake rates (left hand side); the second strategy is selective root placement (SRP) into nutrient-rich patches, and lower overall RLD (right hand side). b) In the experiment, we used pots with either heterogeneous (left hand side) or homogeneous (right hand side) nutrient distributions. Pots contained similar total amounts of nutrients (mostly in the form of potting soil), but in the heterogeneous treatment, these were concentrated in one quadrant $(\mathrm{Q} 1)$. No barriers existed between the quadrants, so plants could grow freely into the patch or other parts of the pot. Plants were planted in Q2 and Q4 and belowground measurements were done in Q1 and Q3, the patch and opposite quadrant 
2. How does performance in competition (both aboveground and belowground) depend on nutrient distributions and neighbor identity?

3. Can the outcome of competitive interactions be predicted on the basis of root traits? We expect forbs to be particularly successful in competition in heterogeneous soils as a result of high SRP, and grasses to win in homogeneous soils because of high root density combined with high uptake rates.

\section{Materials and methods}

Species selection

We selected eight species for this study: four grasses (Anthoxanthum odoratum, Festuca rubra, Phleum pratense and Poa pratensis) and four forbs (Centaurea jacea, Knautia arvensis, Leucanthemum vulgare and Plantago lanceolata), all common and frequently cooccurring grassland species in Western-Europe. Species will be referred to by their generic name from here on. Seeds were obtained from commercial suppliers (Rieger Hoffmann GmbH, Blaufelden-Raboldshausen, Germany and Saaten Zeller e.K., Riedern, Germany). Seeds were sterilized with chloride gas for $2: 45 \mathrm{~h}$ and subsequently sown in seed flats on gamma-ray sterilized sand and kept moist with deionized water. Seeds were germinated in a climate chamber (14:10 light:dark, $\left.22^{\circ} \mathrm{C}\right)$.

\section{Growing conditions}

Three weeks after seeding, plants were transplanted into pots of $2.4 \mathrm{~L}$ (17 cm diameter, $17 \mathrm{~cm}$ high; soil depth approximately $15.5 \mathrm{~cm}$ ). Two plants were grown in all possible pairwise combinations (i.e. 36 combinations). At the start of the experiment, 15 seedlings per species (45 for Poa due to its small size) were harvested to quantify initial biomass (ranging from $0.50 \mathrm{mg}$ ( $\mathrm{Poa}$ ) to $5.42 \mathrm{mg}$ (Centaurea); Table S1).

Plants were subjected to one of two soil treatments: either homogeneous or heterogeneous soil nutrient distribution. All pots were divided into four quadrants (Q1Q4) with a metal frame to accommodate the filling of each quadrant with a specific substrate; this metal frame was removed after filling, hence no barriers existed in the pot during the growing period (Fig. 1b). In the heterogeneous soil treatment, one quadrant of the pot (Q1, the so-called patch) was filled with nutrient-rich soil (a mixture of 1:4:1 (v:v:v) sand, loamy sand and potting soil) and the remainder of the pot (Q2-Q4, including the quadrant opposing the patch, Q3) was filled with a nutrient poor mixture (4:1 (v:v) sand and loamy sand. In the homogeneous soil treatment, the entire pot (Q1-Q4) was filled with a 'medium' mixture of both soils (13:7:1 (v:v:v) sand, loamy sand and potting soil), so that the total nutrient content of a pot would be similar in both the homogeneous and heterogeneous treatments. After filling the pots, two plants of the same or of different species were randomly assigned to and placed in the middle of Q2 and Q4 (home quadrants), respectively, leaving two quadrants (Q1 and Q3) unoccupied.

Extractable nitrogen $\left(\mathrm{NO}_{3}{ }^{-}-\mathrm{N}\right.$ and $\mathrm{NH}_{4}{ }^{+}-\mathrm{N}$ in $\mathrm{mg} \mathrm{kg}$ ${ }^{1}$ dry soil) was determined by adding $50 \mathrm{ml}$ of $0.5 \mathrm{M}$ $\mathrm{KCl}$ solution to soil samples (18-23 g fresh mass), shaking the mixtures for $1 \mathrm{~h}$, and analyzing the nutrients in the filtered extracts (Auto Analyzer 3 system, Bran + Luebbe, Norderstedt, Germany). Extractable $\mathrm{PO}_{4}{ }^{3-}$ was determined in $50 \mathrm{ml}$ of $0.5 \mathrm{M} \mathrm{NaHCO}_{3}$ solution (added to 4-6 g fresh mass, shaken for $0.5 \mathrm{~h}$ ). Nutrient concentrations at the start of the experiment were $35.9 \pm 3.5$ (rich), $12.5 \pm 4.1$ (poor) and $26.3 \pm 3.8$ (homogeneous) mg $\mathrm{NO}_{3}{ }^{-}-\mathrm{N} \mathrm{kg}^{-1}$ dry soil; $9.0 \pm 1.2$ (rich), $3.3 \pm 0.6$ (poor), and $4.3 \pm 0.5$ (homogeneous) $\mathrm{mg} \mathrm{NH}_{4}{ }^{+}-\mathrm{N} \mathrm{kg}^{-1}$ dry soil; $31.5 \pm 1.4$ (rich), $11.4 \pm 0.5$ (poor) and 15.8 \pm 0.4 (homogeneous) $\mathrm{mg} \mathrm{PO}_{4}{ }^{3-}-\mathrm{P} \mathrm{kg}^{-1}$ dry soil.

We measured from a separate set of pots without plants the release of $\mathrm{N}$ and $\mathrm{P}$ from the soil over time $(\mathrm{t}=0,1,4$ and 7 weeks; $n=4$ per time point; see Figure S1). Nutrient concentrations were always different between soil types (all $P<0.01$ ). Total extractable $\mathrm{N}$ and $\mathrm{NO}_{3}{ }^{-}$increased over the course of the experiment $(P<0.001)$ and were 2.5-3 times as high in the rich as in the poor soil at all times. Extractable $\mathrm{PO}_{4}{ }^{3-}$ decreased somewhat over the course of the experiment in rich soil while it stayed the same in medium and poor soil (time $\mathrm{x}$ soil: $P<0.001$ ); however, at $\mathrm{t}=7$ weeks, $\mathrm{PO}_{4}{ }^{3-}$ concentrations in rich soil were still 2 times as high as concentrations in poor soil.

Each plant-soil treatment combination was replicated eight times, giving 576 pots, distributed over two blocks ( $n=3$ and $n=5$ ) with a two-week time lag. Plants were grown for 8 weeks, and watered with deionized water three times a week or as needed. To avoid soil drying the amount of water was gradually increased over the 
course of the experiment as leaf surface area and transpiration increased.

Simultaneously with the first block, we grew single plants ( 1 per pot, $n=3-5$, harvested after 59 days) in homogeneous soil, to estimate the potential relative growth rate (RGR) and background tracer values (see below). These were also to test whether single plants grow larger than plants in pairwise setting, to show that competition actually occurred in this experiment.

\section{Tracers}

To estimate nutrient uptake rates in monocultures and mixtures at the end of experiment from the patch (Q1) and opposite quadrant $(\mathrm{Q} 3)$, we injected rubidium $(\mathrm{Rb})$ and lithium (Li), two potassium-surrogate cations (Kabata-Pendias and Pendias 2000), as tracers at the end of the experimental period (Casper et al. 2003; Hoekstra et al. 2014). Rubidium was injected in Q1 and $\mathrm{Li}$ in Q3. In the middle of both these quadrants, a $9 \mathrm{~cm}$ deep, $3 \mathrm{~mm}$ wide hole was made using a thin wooden stick. Using a $10 \mathrm{ml}$ dispenser, connected to a hollow needle with lateral holes at $1.5 \mathrm{~cm}$ from the tip, we injected $3.1 \mathrm{ml}$ of $0.2 \mathrm{M}$ rubidium chloride or lithium chloride solution at $7.5 \mathrm{~cm}$ depth in Q1 and Q3 (Fig. 1b). This corresponded to $0.62 \mathrm{mmol}$ pure tracer $(52.99 \mathrm{mg}$ $\mathrm{Rb}$ or $4.30 \mathrm{mg} \mathrm{Li}$ ) per injection. The tracers were applied $46 \mathrm{~h}$ before harvest.

\section{Harvest}

Plants were harvested block-wise after 8 weeks growth. We harvested both aboveground and belowground biomass. Due to time constraints the $8^{\text {th }}$ replicate was only harvested aboveground. The aboveground material was cut at soil level, $46 \mathrm{~h}$ after $\mathrm{RbCl}$ and $\mathrm{LiCl}$ application. Subsequently, a $1.8 \mathrm{~cm}$ diameter soil core was taken in the middle of the patch and the opposite quadrant (Q1 and $\mathrm{Q} 3$ ), around the $\mathrm{RbCl}$ and $\mathrm{LiCl}$ injection points. Roots in this sample $\left(39.4 \mathrm{~cm}^{3}\right.$ soil) were washed with care. Approximately $50 \mathrm{mg}$ of fresh root material was then immediately frozen at $-80^{\circ} \mathrm{C}$ and used for molecular quantification of species proportions in the sample (Mommer et al. 2008). With these root cores, we captured 5-6\% of root mass in each quadrant (homogeneous Q1: $5.7( \pm 0.11), Q 3: 5.7( \pm 0.14)$, heterogeneous Q1: 4.9 ( \pm 0.34$),$ Q3: 6.3 ( \pm 0.36$)$ ). Subsequently, all quadrants of the pot were washed out separately using sieves of $0.2 \mathrm{~mm}$ gauze and roots were collected using tweezers. In the monoculture pots, a subsample was taken directly from total root mass of Q1 and Q3 for determination of SRL. These roots were stored in $0.01 \% \mathrm{HgCl}$ with $0.035 \%$ Neutral Red to preserve and stain the roots, and were stored at $4{ }^{\circ} \mathrm{C}$ for up to 5 weeks. Root length was determined from root scans (600 dpi, Epson Expression 10000 XL scanner, Regent Instruments, Quebec, Canada) using WinRhizo software (Regent Instruments). All shoot and root samples were dried at $65^{\circ} \mathrm{C}$ for at least $48 \mathrm{~h}$ and weighed (Sartorius, Nieuwegein, the Netherlands).

Molecular analysis of species proportions in mixed root samples

To estimate the proportion of each of the species in the mixed root samples in Q1 and Q3, we applied the RTPCR method of Mommer et al. (2008) with specific adjustments for this experiment (Methods S1, Table S2, Figure S2) . Species abundances were quantified for four replicates (one from the first and three from the second block). Root biomasses per species per quadrant (Q1 or Q3) were determined based on fresh mass of the root sample multiplied by the fraction of the species in that sample as determined by RT-PCR. Separate monocultures of all species $(n=5$ per species, two plants per pot, 4:1 (v:v) sand: loamy sand soil mixture) were grown in the greenhouse for 8 weeks (December 2013 - February 2014) to determine the ratio between fresh mass and dry mass in roots. These ratios were used to calculate species-specific dry root mass per sample, hence, per quadrant.

Nutrient analyses: tracer concentrations

The dried aboveground material of four monocultures per species was pulverized. Up to $200 \mathrm{mg}$ acid digested with $4 \mathrm{ml} 65 \%$ nitric acid, plus $1 \mathrm{ml} 30 \%$ hydrogen peroxide to start the digestion reaction (ETHOS laboratory microwave, Milestone S.r.L., Sorisole, Italy). The destruate was solved in 50 or $100 \mathrm{ml}$ ultra-deionized water. $\mathrm{Rb}$ and $\mathrm{Li}$ concentrations in the destruate were measured with mass spectrometry (ICP-MS, Thermo Fischer Scientific, Waltham MA, USA). We recovered on average $3.04 \pm 0.11 \mu \mathrm{mol} \mathrm{Rb}$ and $0.81 \pm 0.04 \mu \mathrm{mol}$ $\mathrm{Li}$. This corresponds to $0.49 \%$ of the $\mathrm{Rb}$ and $0.13 \%$ of the $\mathrm{Li}$ injected per pot $(620 \mu \mathrm{mol})$. Note that we did not measure $\mathrm{Rb}$ and $\mathrm{Li}$ concentrations in the roots of the plants, as roots were derived from both competing plants 
per pot together, and obtaining species-specific data would thus have been impossible in mixtures.

\section{Calculations}

Competitive success was approximated by aboveground biomass per plant, and the relative yield per plant.

Relative yield As a measure of performance in competition, we used Relative Yield per Plant (RYP, sensu Engel and Weltzin 2008). This metric is calculated as

$$
R Y P_{i j}=\frac{Y_{i j}}{Y_{i i}}
$$

where $Y_{i i}$ is the biomass produced by the target $\mathrm{i}$ species in monoculture in homogeneous soil (functioning as a baseline in the most neutral conditions) and $\mathrm{Y}_{\mathrm{ij}}$ the biomass produced by the target species $\mathrm{i}$ in combination with neighbouring species $\mathrm{j}$ in either homogeneous or heterogeneous soil. If biomass per plant in interspecific competition is the same as in monoculture, then $\mathrm{RYP}=1$. If plants are less hampered by interspecific neighbours than intraspecific neighbours, RYP $>1$ projects them as having advantage of competition, usually at the expense of the competitor. The competitive hierarchy was determined by mean RYP of the target species, from high to low.

Relative growth rate ( $R G R$ ) Selective Root Placement (SRP) and plant performance are affected by potential RGR resulting in size differences between species at harvest (Fransen et al. 1999). We therefore included differences in RGR in the analyses of plant performance. RGR was calculated from single plants in homogeneous soil, as

$R G R=\left(\ln W_{2}-\ln W_{1}\right) /\left(t_{2}-t_{1}\right)$

with $t_{1}$ being the start of the experiment, $t_{2}$ the day the plants were harvested ( 59 days after $\left.\mathrm{t}_{1}\right), \mathrm{W}_{1}$ the mass of a seedling at planting, and $\mathrm{W}_{2}$ the dry aboveground mass at harvest.

Root traits SRL in monoculture was calculated based on scanned subsamples as root length per gram dry root mass. RLD was based on root mass per quadrant (species proportions from RT-PCR analysis, see above) and mean SRL in monoculture per species.

We calculated Selective Root Placement (SRP) per individual based on species-specific root biomass in Q1 (nutrient-rich patch in the heterogeneous treatment) and Q3 (opposite quadrant with background soil), as

$\frac{\text { biomass Q1-biomass Q3 }}{\text { biomass Q1 + biomass Q3 }}$

This metric can range between 1 (all biomass in Q1) and -1 (all biomass in Q3). An SRP of 0 means that the plant did not specifically place more roots in either of the quadrants.

Cation uptake rates in monocultures were calculated from concentrations in the aboveground plant material (see above: Nutrient analyses), total aboveground biomass, and root length in the core/sample in Q1 and Q3, respectively, and expressed as $\mu \mathrm{mol} \mathrm{m}{ }^{-1}$ root $46 \mathrm{~h}^{-1}$. Kanalogues have comparable mobility in soil as $\mathrm{K}$, with Li probably somewhat more mobile than $\mathrm{Rb}$ (Hoekstra et al. 2014).

\section{Statistical analysis}

All statistical analyses were performed in $\mathrm{R}$ version 3.1.2 R-Core-Team (2014)). Linear mixed-effects models were constructed using the function 'lme' of the package 'nlme'; simple linear models were constructed using ' $1 \mathrm{~m}$ ' of the package 'stats'. ANOVA summaries (sequential; type I sums of squares, and marginal; type III sums of squares) were obtained with 'anova' from 'stats'. All models described below were split for factor levels when appropriate.

To test hypothesis 1 , we analyzed differences in trait values between monocultures of the eight species, for both phylogenetic group (grasses vs forbs) and overall species differences. Six (root) traits, being potential RGR in single plants, and SRL, mean RLD over Q1 and Q3, SRP (mass in $\mathrm{Q} 1$ relative to mass in $\mathrm{Q} 1+\mathrm{Q} 3$ together), $\mathrm{Rb}$ uptake rate from Q1 and Li uptake rate from Q3 from monocultures were analyzed with mixed-effects models. Species was a fixed factor and was tested for all traits independently; or when testing phylogenetic group effects, the factor 'species' was replaced with a two-level fixed factor coding for grass or forb. The treatment nutrient distribution was analyzed differently for different traits: nutrient level of the patch (three levels: rich, poor and 
homogeneous, the latter the average from the two quadrants in the homogeneous treatment) was tested for SRL and RLD, whereas for $\mathrm{Rb}$ and $\mathrm{Li}$ uptake rates two levels were compared: homogeneous and heterogeneous pots. Potential RGR was analyzed only between species, as this was measured on single plants in homogeneous soil only. SRP was analyzed between species on heterogeneous soil only. For SRP values it was additionally assessed whether they deviated from 0 with a one-sided $t$-test (function 't.test' from the package 'stats'). SRL, RLD and Rb and Li uptake rates were log-transformed to meet assumptions of ANOVA; SRP and RGR were analyzed as untransformed values.

We tested the correlations between these traits with simple Spearman's correlation tests between species means, for homogeneous and heterogeneous nutrient distributions separately. We also tested how the traits measured in monoculture were correlated to traits in mixture.

To confirm that competition affected individual plant biomass, we tested if individual biomass aboveground was reduced in competition compared to when growing alone. We tested this on square-root transformed biomass with mixed-effects ANOVA, with species and growing conditions (single or intraspecific competition) as fixed factors, and block as random factor.

To test hypothesis 2, we analyzed the effects of neighbor species and nutrient distribution on biomass. Belowground biomass per core (in Q1 or Q3) was square-root transformed and analyzed with a mixedeffects model, with target, neighbor and soil nutrient level of the patch (three levels: rich, poor and average homogeneous) as fixed factors and quadrant within pot within block as random part of the model (to account for multiple measurements on two individuals per pot).

Aboveground biomass (square-root transformed) was analyzed with a mixed-effects model, with target, neighbour and nutrient distribution (homogeneous or heterogeneous) as fixed factors, and pot within block as random model. A significant interaction between target and neighbour would indicate different competitive outcomes depending on neighbour species. An interaction between target, neighbour and nutrient distribution would indicate that this competitive outcome differs between nutrient distributions.

To test hypothesis 3 , we assessed whether trait values were correlated to competitive success in mixtures. We defined competitive success as the RYP of each plant. We used the traits potential RGR, SRP (only in heterogeneous soil), RLD (mean of Q1 and Q3), Rb uptake rate and Li uptake rate. We tested correlations among the monoculture values of the traits of interest (Table S4) and found that the values were correlated, but mostly not significantly, and with low correlation coefficients. Therefore, we deemed it acceptable to use them all as independent factors in multiple regression models. We did not include SRL in the analyses for two reasons. First, we could measure this trait only in monocultures, not in interspecific mixtures. Second, SRL was the only trait with a strong positive correlation with RGR and a strong negative correlation with SRP (Table S4), precluding an independent analysis. For $\mathrm{Rb}$ and $\mathrm{Li}$ uptake rate, outlier values were removed $\left(>100 \mu \mathrm{mol} \mathrm{m}^{-1}\right.$ root $46 \mathrm{~h}^{-1}$ for $\mathrm{Rb}$ uptake rate and $>60 \mu \mathrm{mol} \mathrm{m} \mathrm{m}^{-1}$ root $46 \mathrm{~h}^{-1}$ for $\mathrm{Li}$ uptake rates). We created multiple regression models with RYP of each plant as response variable in two different ways. First, the explanatory variables used were mean trait values, as measured in monoculture (or for potential RGR: in single-growing plants). These will be referred to as 'monoculture values'. Second, plant performance was regressed on trait values measured on the plants in each of the replicates in each of the treatments. These values will be referred to as 'mixture values' (although they include the values of each of the monoculture plants as well). Separate models were constructed for homogeneous and heterogeneous nutrient distributions, including trait values and trait values in interaction with phylogenetic group (grass vs forb). Then, to detect differences between phylogenetic groups according to our hypothesis 3 (Fig. 1a), models were also created for grasses and forbs separately. In the homogeneous nutrient distribution, SRP was omitted as an explanatory variable. For all these models, we performed step-wise model reduction using the function stepAIC from the 'MASS' package in R. This function uses Akaike's Information Criterion (AIC; Akaike 1974) to compare models and stops reducing a model when this gives no further decrease in the AIC. We tested both the full models and the step-wise reduced models with a type III ANOVA.

\section{Results}

Trait values in monocultures

Species differed in trait values in monoculture, mostly as hypothesized under (1). Relative growth rate (potential 
soils

rich soil (from heterogeneous nutrient dist.)

poor soil (from heterogeneous nutrient dist.)

medium soil (from homogeneous nutrient dist.)

nutrient dist

heterogeneous

homogeneous
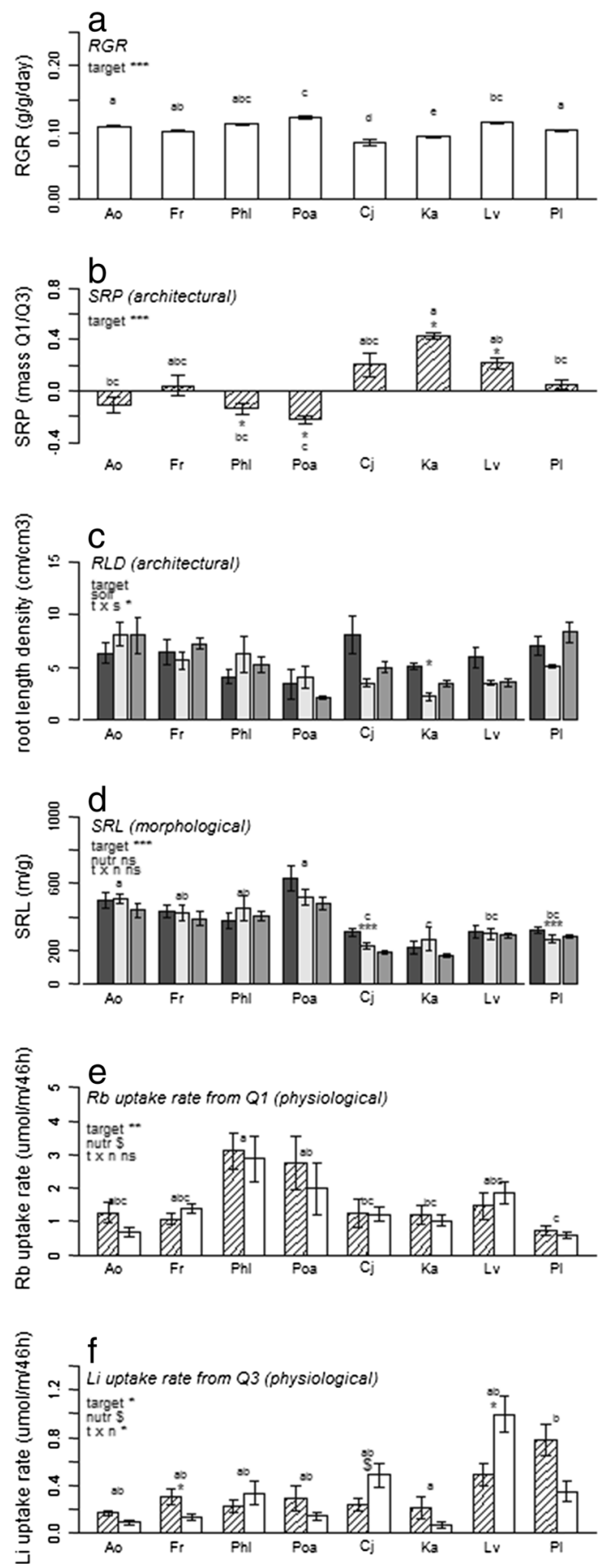

Fig. 2 Values of traits of all species, measured in monoculture (SRL, RLD, SRP, Rb uptake rate and Li uptake rate) or as isolated plants (potential RGR). RLD and SRL (panels c, d) were measured in rich soil and poor soil (both from heterogeneous nutrient distribution) as well as in medium soil (from homogeneous nutrient distribution). Uptake rates (panels e, f) were measured both in heterogeneous and homogeneous nutrient distribution. Different letters above sets of bars indicate significant differences between species means. Stars indicate significant differences between treatments within species. Error bars indicate 1 SE. Species: Ao = Anthoxanthum odoratum, Fr = Festuca rubra, $\mathrm{Phl}=$ Phleum pratense, $\mathrm{Poa}=$ Poa pratensis, $\mathrm{Cj}=$ Centaurea jacea, $\mathrm{Ka}=$ Knautia arvensis, $\mathrm{Lv}=$ Leucanthemum vulgare, $\mathrm{Pl}=$ Plantago lanceolata

RGR) was significantly different among species $\left(F_{7,31}=41.46, P<0.001\right)$ and between grasses and forbs, with grasses on average having the higher RGR $\left(\mathrm{F}_{1,37}=13.80, P<0.001\right)$ (Fig. 2a). Selective root placement (SRP) differed significantly among species (target: $\mathrm{F}_{7,22}=5.93, P=0.001$ ) (Fig. 2b), and between forbs and grasses $\left(\mathrm{F}_{1,5528}=18.16, P<0.001\right)$. SRP was on average significantly higher than 0 for forbs $\left(\mathrm{t}_{31}=5.35\right.$, $P<0.001)$, but lower than 0 for grasses $\left(t_{29}=-2.39\right.$, $P=0.023$ ).

Root length density (RLD) was significantly different among species $\left(\mathrm{F}_{7,51}=6.45, P<0.001\right)$, without a significant difference between grasses and forbs $\left(\mathrm{F}_{1,57}=0.83, P=0.367\right)$ (Fig. 2c). In addition, differences between species depended on soil nutrients (target x soil: $\left.\mathrm{F}_{14,15}=2.79, P=0.029\right)$. The latter effect also occurred at the phylogenetic group level (FG x soil: $\left.\mathrm{F}_{2,27}=9.96, P<0.001\right)$ : forbs overall had lower root mass in poor than in rich or medium soil $\left(\mathrm{F}_{2,14}=11.41, P=0.001\right)$ while the grasses did not show significant differences in RLD between soil types (Fig. 2b).

Specific root length (SRL) (Fig. 2d) was significantly different among species $\left(\mathrm{F}_{7,96}=13.35, P<0.001\right)$ with grasses overall having higher SRL than forbs $\left(\mathrm{F}_{1,102}=53.38, P<0.001\right)$. However, no significant differences in SRL were found between soil types $\left(\mathrm{F}_{2,73}=1.02, P=0.365\right)$.

Rubidium uptake rate from Q1 (the 'rich' quadrant; $\mu \mathrm{mol} \mathrm{m}{ }^{-1}$ root $46 \mathrm{~h}^{-1}$ ) was significantly different between species $\left(\mathrm{F}_{7,43}=4.28, P=0.001\right)$ (Fig. 2e). On average, uptake rates were higher in grasses than in forbs $\left(\mathrm{F}_{1,55}=9.01, P=0.004\right)$. None of the species showed a significantly different uptake rate in heterogeneous compared to homogeneous nutrient distribution. 
Lithium uptake rates from Q3 (the 'poor' quadrant; $\mu \mathrm{mol} \mathrm{m} \mathrm{m}^{-1}$ root $46 \mathrm{~h}^{-1}$ ) were also different among species $\left(\mathrm{F}_{7,43}=2.34, P=0.040\right)$ (Fig. 2f). There was no overall difference in Li uptake rates between grasses and forbs $\left(\mathrm{F}_{1,55}=1.08, P=0.304\right)$. However, in contrast to $\mathrm{Rb}$ uptake rates, species responses to nutrient treatment (hence, poor or homogeneous soil) were different for Li uptake rates (target $\mathrm{x}$ nutrient: $\mathrm{F}_{7,43}=2.94$, $P=0.013$ ). In general, the relationships between the different traits in monoculture were weak (Table S4).

Species performance under competition

Competition occurred between individuals in pairwise setting, as they were on average $40 \%$ smaller than single plants, except for the smallest species, Poa (Figure S3; Table S3: competition: $\mathrm{F}_{1,143}=27.54$, $P<0.001)$.

Both belowground biomass per quadrant (Fig. 3; Table 1), and aboveground biomass (Fig. 4; Table 2) were significantly different between species, both overall (Table 1 and 2) and in monocultures (not shown). Neither aboveground nor belowground biomass depended on nutrient distribution.

Both belowground and aboveground, target species biomass was dependent on neighbour. Belowground, the effect of neighbour on root biomass differed between target species (significant target $\mathrm{x}$ neighbour), meaning that the competitive relationships were not fully hierarchical (i.e., it differed depending on the target species considered). However, the effect of neighbour or the competitive hierarchy was not affected by soil type (significant neighbour $\mathrm{x}$ soil and target $\mathrm{x}$ neighbour $\mathrm{x}$ soil interactions). Aboveground, the competitive responses were hierarchical, as the effect of neighbour identity was similar for each target species (no target $\mathrm{x}$ neighbour interaction). This hierarchy was also not affected by soil nutrient conditions, contrary to our hypothesis 2 . The aboveground competitive response hierarchy could be defined as Plantago $>$ Leucanthemum $>$ Anthoxanthum $>$ Phleum $>$ Poa $>$ Festuca $>$ Knautia $>$ Centaurea. RYP ranged from $1.27 \pm 0.03$ in Plantago, to $0.71 \pm 0.03$ in Centaurea.

Traits related to competitive success

Potential RGR and RLD were the two traits that best explained species competitive ability, measured as Relative Yield per Plant (RYP) (Table 3). This was the case both when looking at mean monoculture trait
Fig. 3 Belowground root mass per quadrant of all species against all competitors, in three soil types (rich and poor from the heterogeneous nutrient distribution, and medium soil from the homogeneous nutrient distribution). Each panel (a-h) represents a target species with bars for biomass when grown with eight different competitor species. The intraspecific competitor (monoculture) is underlined. The dashed line is at the level of monoculture biomass in homogeneous conditions. Stars indicate significant differences between soil types within a speciesneighbor combination. Error bars indicate 1 SE. Competitor species: Ao $=$ Anthoxanthum odoratum, Fr = Festuca rubra, $\mathrm{Phl}=$ Phleum pratense, $\mathrm{Poa}=$ Poa pratensis, $\mathrm{Cj}=$ Centaurea jacea, $\mathrm{Ka}=$ Knautia arvensis, $\mathrm{Lv}=$ Leucanthemum vulgare, $\mathrm{Pl}=$ Plantago lanceolata . Note the differently scaled y-axes for Poa and Plantago

values and trait values measured in mixtures. RGR and RLD were well correlated between mixtures and monocultures (Table S5; correlation coefficients $0.42-0.69$ ). The percentage of explained variation in the regression models was higher for mixture trait values than for mean monoculture values (Table 3; 2-37 \% versus 11-49\%). In models of grasses and forbs together, the effect of either RGR or RLD (or both) differed between phylogenetic groups (shown by a statistical interaction), which is why we split the models between phylogenetic groups. Nevertheless, RGR and RLD appeared as best explanatory variables for all species together and also for forbs and grasses separately, as well as for homogeneous and heterogeneous soils. SRL, not included in the models, may have contributed to competitive success, given its positive correlation with RGR (Table S4).

Table 1 Summary of linear mixed-effects ANOVA (type III sums of squares) of individual root biomass in samples (in Q1 and Q3) against all competitors (intraspecific and interspecific), in three soil types: rich and poor (from Q1 and Q3 in heterogeneous nutrient distribution) and medium (average of Q1 and Q3 in homogeneous nutrient distribution)

\begin{tabular}{lllll}
\hline & numDF & denDF & F-value & p-value \\
\hline Intercept & 1 & 479 & 228.85633 & $<.0001$ \\
Target & 7 & 479 & 12.41613 & $<.0001$ \\
Neighbour & 7 & 479 & 7.01943 & $<.0001$ \\
Soil & 2 & 134 & 0.74933 & 0.4747 \\
Target x Neighbour & 49 & 479 & 3.45377 & $<.0001$ \\
Target x Soil & 14 & 479 & 2.45056 & 0.0024 \\
Neighbour x Soil & 14 & 479 & 1.20827 & 0.2653 \\
Target x Neighbour x Soil & 98 & 479 & 1.14843 & 0.1763 \\
\hline
\end{tabular}




\section{soils}

rich soil (from heterogeneous nutrient dist.)

poor soil (from heterogeneous nutrient dist.)

medium soil (from homogeneous nutrient dist.)
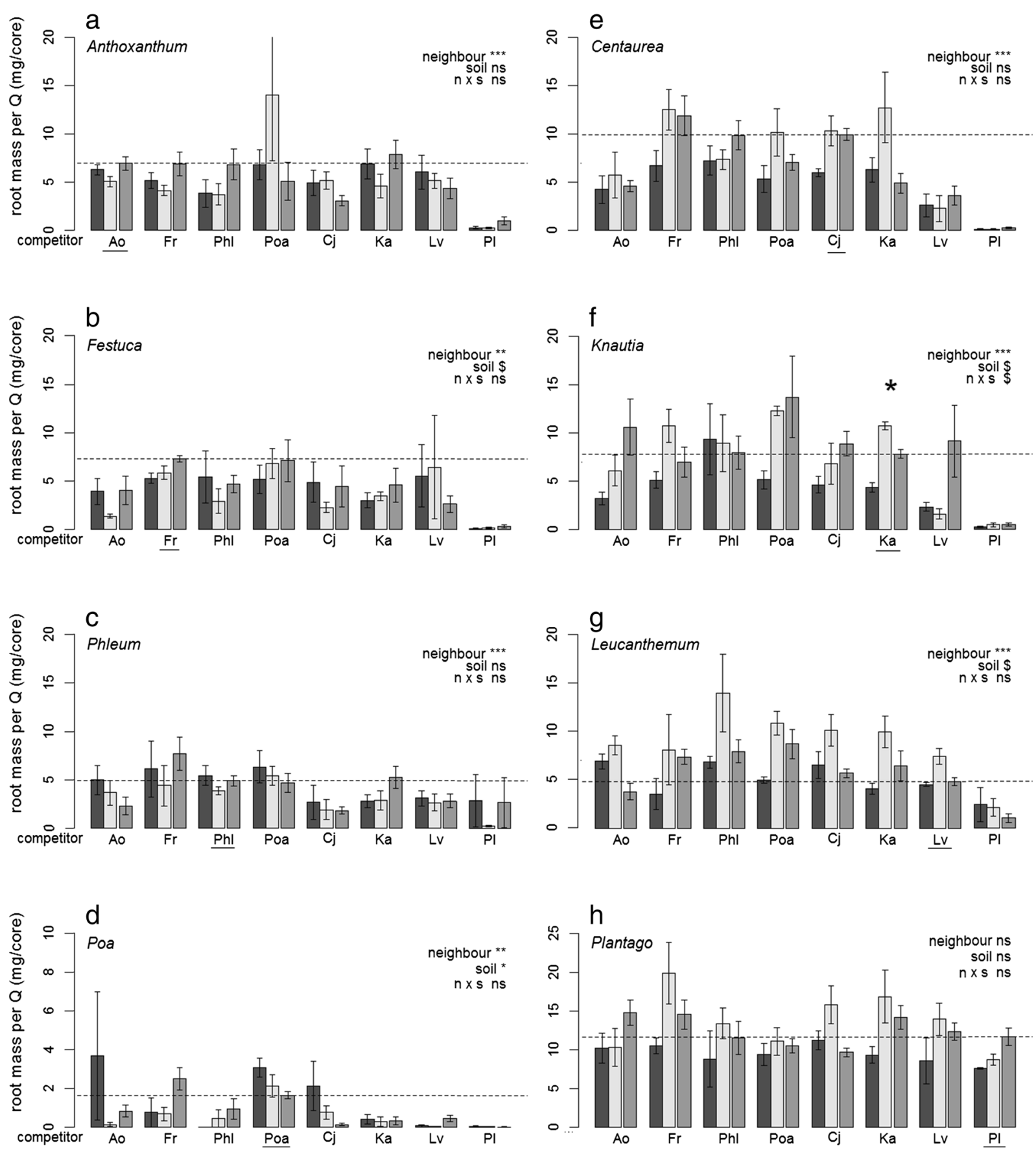

Other traits hardly contributed to explaining the variation in competitive ability between species. $\mathrm{Rb}$ and $\mathrm{Li}$ uptake rate almost invariably dropped out during model reduction, indicating that these traits did not explain 
nutrient dist.

heterogeneous

homogeneous
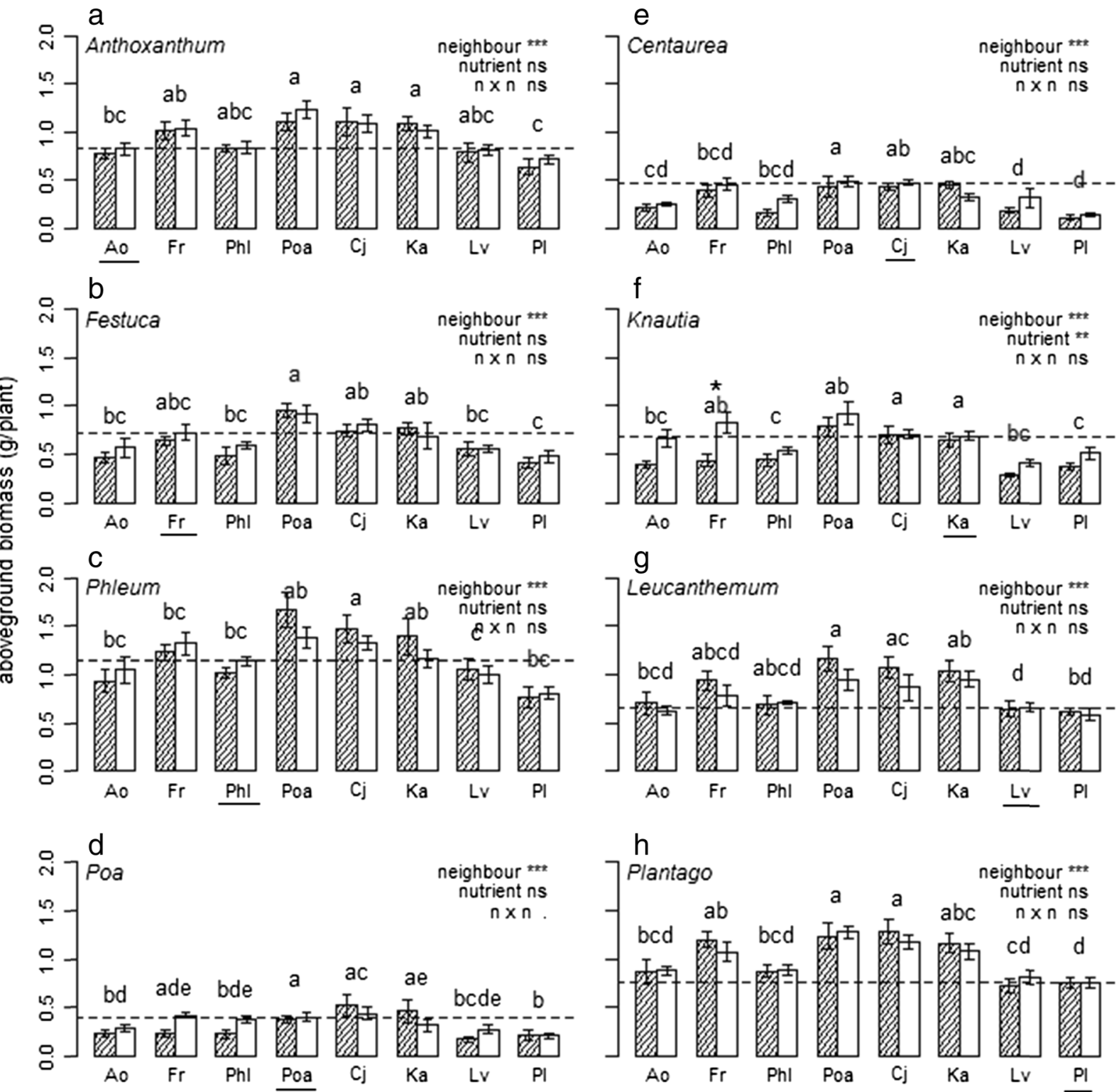

Fig. 4 Aboveground biomass (g per plant) of all target species against all competitor species, in homogeneous and heterogeneous nutrient distributions. Each panel (a-h) represents a target species with bars for biomass with eight competitor species. The intraspecific competitor (monoculture) is underlined. The dashed line is at the level of monoculture biomass in homogeneous conditions. Biomasses above this line translate to RYP $>1$; biomasses below

much variation in RYP. In heterogeneous soils, positive correlations between RYP and SRP were not observed this line translate to RYP $<1$. Different letters above sets of bars indicate significant differences between species means. Stars indicate significant differences between treatments within species. Error bars indicate $1 \mathrm{SE}$. Competitor species: Ao=Anthoxanthum odoratum, $\mathrm{Fr}=$ Festuca rubra, $\mathrm{Phl}=$ Phleum pratense, $\mathrm{Poa}=$ Poa pratensis, $\mathrm{Cj}=$ Centaurea jacea, $\mathrm{Ka}=$ Knautia arvensis, $\mathrm{Lv}=$ Leucanthemum vulgare, $\mathrm{Pl}=$ Plantago lanceolata

in reduced models, also not for forbs as hypothesized. Despite some interactions of RGR and RLD with 
Table 2 Summary of linear mixed-effects ANOVA (type III sums of squares) of individual shoot biomass against all competitors (intraspecific and interspecific), in homogeneous and heterogeneous nutrient distribution

\begin{tabular}{lllll}
\hline & numDF & denDF & F-value & $p$-value \\
\hline Intercept & 1 & 546 & 311.04106 & $<.0001$ \\
Target & 7 & 423 & 19.18926 & $<.0001$ \\
Neighbour & 7 & 423 & 4.60226 & 0.0001 \\
Nutrient distribution & 1 & 546 & 0.34902 & 0.5549 \\
$\quad$ ND) & 49 & 423 & 0.89398 & 0.6773 \\
Target x Neighbour & 7 & 423 & 0.83762 & 0.5565 \\
Target x ND & 7 & 423 & 0.23653 & 0.9762 \\
Neighbour x ND & 49 & 423 & 0.61253 & 0.9818 \\
Target x Neighbour x ND & 49 & & & \\
\hline
\end{tabular}

phylogenetic group, we found that forbs and grasses did not markedly differ in the traits conferring competitive ability in this experiment.

\section{Discussion}

Root traits: Species-specific vs. phylogenetic group differences

Our trait analyses clearly showed plant species differ in root traits, confirming our first hypothesis. Interestingly, for some traits the differences mainly occurred between phylogenetic groups (selective root placement, SRP; specific root length, SRL), while for others no differences between phylogenetic groups were found (root length density, RLD) despite clear differences between species. Taken together, our results suggest that the functional distinction between grasses and forbs, commonly treated as two functional groups (Kembel and Cahill 2005; Roscher et al. 2004; Tilman et al. 1997) holds for some root traits, but not for others. This may explain why a functional group approach to effects of species richness is successful in some cases (e.g., Marquard et al. 2009), but not in others (e.g., Wright et al. 2006). The importance of traits for the ecological process under study will determine whether a functional distinction in grasses and forbs will prove useful.

Competition belowground and aboveground

Overall, we found a clear competitive hierarchy, with grasses and forbs mingled along the hierarchy. Despite differences in root traits, grasses and forbs did not occupy different positions in the competitive hierarchies of homogeneous and heterogeneous soil nutrient conditions. The competitive hierarchy was most marked aboveground, independent of target-neighbor combinations. Belowground, the performance of species in competition was significantly affected by both neighbor identity and nutrient distribution. Although we watered frequently and avoided dry soil throughout, water availability and differences in water availability between the patch and background soil could have influenced the competitive outcome. Despite this, it showed strong similarities to the aboveground hierarchy.

The consistent competitive hierarchy aboveground suggests that plastic root responses buffered aboveground biomass against the effects of soil heterogeneity and interspecific competition on root biomass. Generally, plants are capable of highly plastic root responses to a variety of soil conditions, while achieving similar performance aboveground (Jansen et al. 2006; Mommer et al. 2011; Padilla et al. 2013), suggesting that root traits might have compensated for differences in soil conditions in our experiment. However, we did not find that different traits could explain competitive success in homogeneous vs. heterogeneous soils (see below).

\section{Linking competition to traits}

In the present experiment, we showed that potential RGR and RLD were overall the best explanatory variables for competitive success. High RGR results in large plants, and plant competitive success is usually found to be correlated with size (size-symmetric, or beyond: sizeasymmetric; Casper and Jackson 1997). In the present study, we also found that size of the root system (measured as RLD) conferred competitive success, and RLD in monoculture was a good predictor for species-specific RLD in mixtures. This is in accordance with findings of the importance of RLD for competitive ability, both in homogeneous (Casper and Jackson 1997; Rajaniemi 2007) and heterogeneous (Mommer et al. 2011) soils.

We found that SRP explained very little variation in competitive success. Between phylogenetic groups, it was positively related to RYP, because forbs, showing higher SRP, did a bit better in the competitive hierarchy on average. However, within phylogenetic groups, it was not (grasses) or negatively (forbs) correlated to RYP. Also, in contrast to RLD, SRP in monoculture 


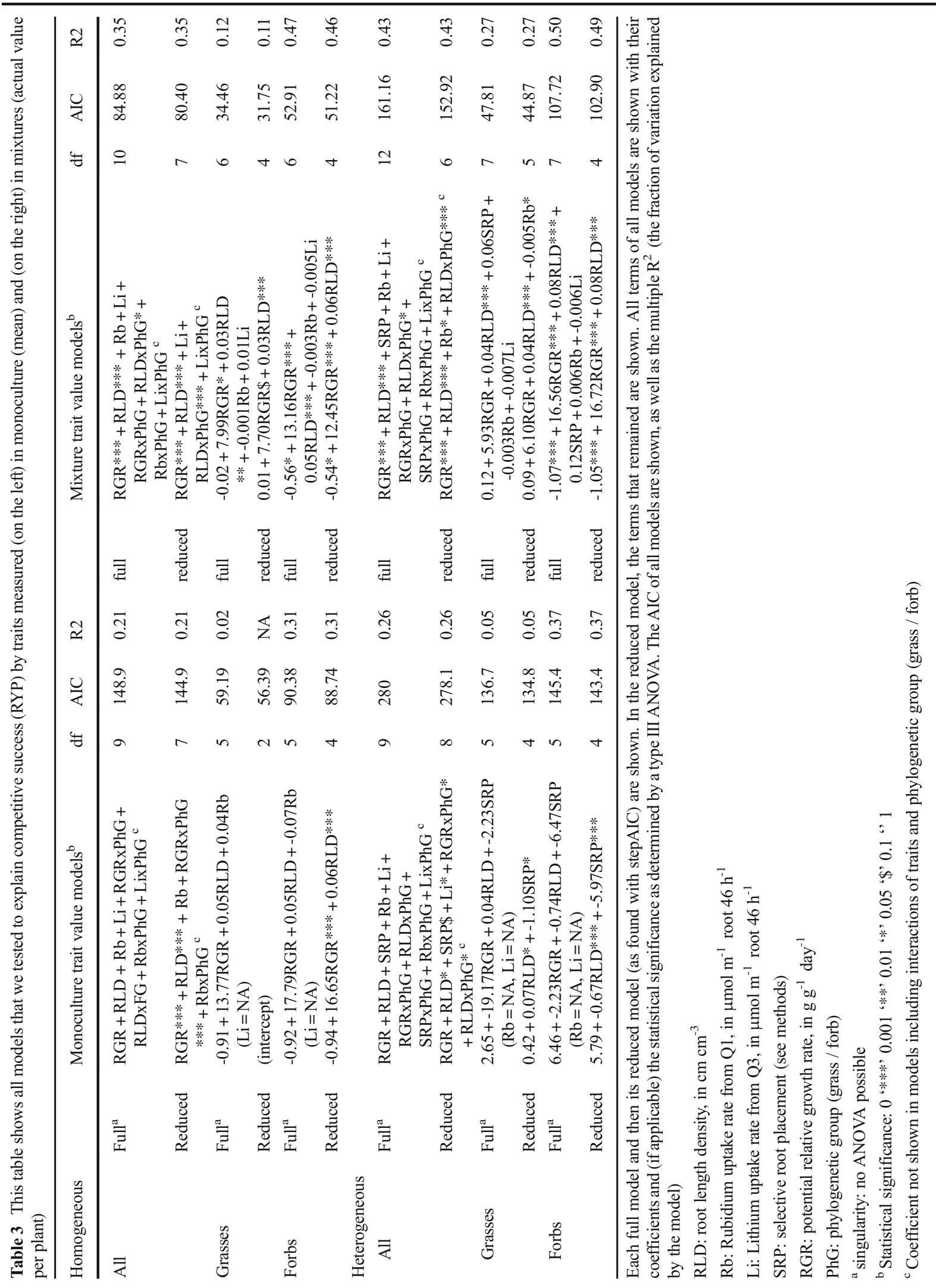


and SRP in mixtures correlated poorly. This adds to the observation of McNickle et al. (2015) that SRP in single plants did not predict SRP in plants in competition. Together, these results may very well be an explanation why previous experiments measuring SRP sometimes yielded such contradictory results (Bliss et al. 2002; Cahill and Casper 1999; Fransen and De Kroon 2001; Fransen et al. 2001; Mommer et al. 2011).

Contrary to our hypothesis 3 , neither $\mathrm{Rb}$ nor $\mathrm{Li}$ uptake rates from either the rich patch or the opposite quadrant (Q1 and Q3) were linked to competitive success. Size-related traits (i.e. potential RGR and RLD) seemed to be overwhelmingly more important for competitive success than nutrient uptake rates. However, due to the variation in the data, some caution should be taken regarding interpretation of the $\mathrm{Rb}$ and $\mathrm{Li}$ uptake rates. It is possible that, in the present experiment, cation transfer to the shoot was still in progress, given the low concentrations in the shoot $(0.49 \%$ of the $\mathrm{Rb}$ and $0.13 \%$ of the $\mathrm{Li}$ injected). Hence, these may not be a good representation of uptake rate, even though a twoday period is generally sufficient to detect relevant differences in pot experiments (Hoekstra et al. 2014).

\section{Consequences for field situations}

Are traits in competition important for community composition in the field and long-term dynamics? Kraft et al. (2015) showed that values in some traits, including rooting depth, were correlated to average fitness differences between species in a one-year field experiment with pairwise competition. The few short-term competition experiments provide us with mixed evidence. Our study shows that some root traits such as uptake rates and SRP correlate poorly to competitive success. However, Fort et al. (2014) showed that the more dissimilar species were in their root trait values, the higher the intensity of competition. This would imply that the weaker competitors in our study (e.g. Centaurea, Festuca, Poa) would simply be outcompeted in the field. Nevertheless, many species coexist for extended periods of time in field situations. This discrepancy might originate firstly from the different importance of traits in the short and the long term, or alternatively from the poor predictive value of single traits per se.

Firstly, on the longer term, other root traits may be more important for competitive success than on the short term. The species used in the present experiment have to some degree different strategies. All species we used in the present experiment occur in the Jena Biodiversity Experiment (Roscher et al. 2004) and some as well in the Wageningen biodiversity experiment (van Ruijven and Berendse 2003), in monocultures and mixtures of 1-60 or 1-8 species, respectively. In these experiments, their competitive performance is not necessarily what we would expect from the present experiment. Some species were dominant in the beginning but lost ground on the long term (Leucanthemum, Knautia; Marquard et al. 2009), while others increased over time (Centaurea, Plantago; van Ruijven and Berendse 2005). Traits contributing to competitive success in the long run may not be detectable in the short term establishment phase such as in our experiment.

Alternatively, single root traits might be useful to predict competitive success in species pairs (Fort et al. 2014; Kraft et al. 2015), but not to predict what will happen in multi-species communities. Recently, a study linked a large set of traits measured in singlegrowing plants to field performance. An analysis on 35 traits of 57 different species showed that root traits significantly improved models that predicted species performance of both single plants in pots and monoculture plots in the field (Schroeder-Georgi et al. 2016). However, the outcomes of multi-species interactions are difficult to predict using traits. Kraft et al. (2015) showed that single traits were poorly correlated to niche differences in the field, and that only combinations of traits could describe niche differences in multiple ecological dimensions. Long-term experimental studies investigating species interactions will be needed to improve our understanding of the relationship between functional traits and competitive success in grasslands.

Acknowledgments The authors thank Bart Aarts, Yvonne Rooijendijk and many other student helpers for their indispensable help with root washing, and Fianne Lubbers for her dedicated assistance in the laboratory. J.M.R. was funded by the German Research Foundation (DFG) as part of the Jena Experiment Phase IV (FOR456/1451) with additional support from the Netherlands Organization for Scientific Research (NWO-ALW). L.M. was supported by a NWO-ALW VENI grant.

Open Access This article is distributed under the terms of the Creative Commons Attribution 4.0 International License (http:// creativecommons.org/licenses/by/4.0/), which permits unrestricted use, distribution, and reproduction in any medium, provided you give appropriate credit to the original author(s) and the source, provide a link to the Creative Commons license, and indicate if changes were made. 


\section{References}

Akaike H (1974) A new look at the statistical model identification. IEEE Trans Autom Control 19:716-723. doi:10.1109/TAC. 1974.1100705

Bardgett RD, Mommer L, de Vries FT (2014) Going underground: root traits as drivers of ecosystem processes. Trends Ecol Evol 29:692-699

Bliss KM, Jones RH, Mitchell RJ, Mou PP (2002) Are competitive interactions influenced by spatial nutrient heterogeneity and root foraging behavior? New Phytol 154:409-417

Cadotte MW, Cavender-Bares J, Tilman D, Oakley TH (2009) Using Phylogenetic, functional and trait diversity to understand patterns of plant community productivity. PLoS ONE 4:e5695. doi:10.1371/journal.pone.0005695

Cahill JF, Casper BB (1999) Growth consequences of soil nutrient heterogeneity for two old-field herbs, Ambrosia artemisiifolia and Phytolacca americana, grown individually and in combination. Ann Bot 83:471-478

Cahill JF Jr., McNickle GG (2011) The Behavioral ecology of nutrient foraging by plants. In: DJ Futuyma, HB Shaffer, D Simberloff (eds) Annual Review of ecology, evolution, and systematics, Vol 42

Casper BB, Jackson RB (1997) Plant competition underground. Annu Rev Ecol Syst 28:545-570

Casper BB, Schenk HJ, Jackson RB (2003) Defining a plant's belowground zone of influence. Ecology 84:2313-2321. doi: 10.1890/02-0287

Comas LH, Eissenstat DM (2009) Patterns in root trait variation among 25 co-existing North American forest species. New Phytol 182:919-928. doi:10.1111/j.1469-8137.2009.02799.x

de Kroon H, Mommer L, Nishiwaki A (2003) Root competition: towards a mechanistic understanding. In: $\mathrm{H}$ de Kroon, EJW Visser (eds) Root Ecology. Springer, Berlin

Díaz S, Lavorel S, de Bello F, Quétier F, Grigulis K, Robson TM (2007) Incorporating plant functional diversity effects in ecosystem service assessments. Proc Natl Acad Sci 104: 20684-20689. doi:10.1073/pnas.0704716104

Engel EC, Weltzin JF (2008) Can community composition be predicted from pairwise species interactions? Plant Ecol 195:77-85. doi:10.1007/s11258-007-9300-2

Farley RA, Fitter AH (1999) The responses of seven co-occurring woodland herbaceous perennials to localized nutrient-rich patches. J Ecol 87:849-859. doi:10.1046/j.1365-2745.1999. 00396.x

Fort F, Cruz P, Jouany C, Field K (2014) Hierarchy of root functional trait values and plasticity drive early-stage competition for water and phosphorus among grasses. Funct Ecol 28:1030-1040. doi:10.1111/1365-2435.12217

Fort F, Jouany C, Cruz P (2012) Root and leaf functional trait relations in Poaceae species: implications of differing resource-acquisition strategies. J Plant Ecol. doi:10.1093/ jpe/rts034

Fransen B, Blijjenberg J, de Kroon H (1999) Root morphological and physiological plasticity of perennial grass species and the exploitation of spatial and temporal heterogeneous nutrient patches. Plant Soil 211:179-189. doi:10.1023/ a:1004684701993

Fransen B, De Kroon H (2001) Long-term disadvantages of selective root placement: root proliferation and shoot biomass of two perennial grass species in a 2-year experiment. J Ecol 89:711-722. doi:10.1046/j.0022-0477.2001.00589.x

Fransen B, de Kroon H, Berendse F (2001) Soil nutrient heterogeneity alters competition between two perennial grass species. Ecology 82:2534-2546. doi:10.1890/0012-9658(2001) 082[2534:snhacb]2.0.co;2

Hodge A (2004) The plastic plant: root responses to heterogeneous supplies of nutrients. New Phytol 162:9-24. doi:10.1111/j. 1469-8137.2004.01015.x

Hodge A, Robinson D, Griffiths BS, Fitter AH (1999) Why plants bother: root proliferation results in increased nitrogen capture from an organic patch when two grasses compete. Plant Cell Environ 22:811-820

Hoekstra NJ, Finn JA, Buchmann N, Gockele A, Landert L, Prill N, Scherer-Lorenzen M, Lüscher A (2014) Methodological tests of the use of trace elements as tracers to assess root activity. Plant Soil 380:265-283. doi:10.1007/s11104-0142048-2

Jansen C, van Kempen MML, Bogemann GM, Bouma TJ, de Kroon H (2006) Limited costs of wrong root placement in Rumex palustris in heterogeneous soils. New Phytol 171: 117-126. doi:10.1111/j.1469-8137.2006.01733.x

Kabata-Pendias A, Pendias H (2000) Trace elements in soils and plants. CRC Press, Boca Raton

Kembel SW, Cahill JF (2005) The evolution of the plant phenotypic plasticity belowground: a phylogenetic perspective on root foraging trade-offs. Am Nat 166:216-230

Kembel SW, De Kroon H, Cahill JF Jr, Mommer L (2008) Improving the scale and precision of hypotheses to explain root foraging ability. Ann Bot 101:1295-1301. doi:10.1093/ $\mathrm{aob} / \mathrm{men} 044$

Kraft NJB, Godoy O, Levine JM (2015) Plant functional traits and the multidimensional nature of species coexistence. Proc Natl Acad Sci 112:797-802. doi:10.1073/pnas.1413650112

Leuschner C, Gebel S, Rose L (2013) Root trait responses of six temperate grassland species to intensive mowing and NPK fertilisation: a field study in a temperate grassland. Plant Soil 373:687-698. doi:10.1007/s11104-013-1836-4

Marquard E, Weigelt A, Temperton VM, Roscher C, Schumacher J, Buchmann N, Fischer M, Weisser WW, Schmid B (2009) Plant species richness and functional composition drive overyielding in a six-year grassland experiment. Ecology 90:3290-3302

McCormack ML, Adams TS, Smithwick EAH, Eissenstat DM (2012) Predicting fine root lifespan from plant functional traits in temperate trees. New Phytol 195:823-831. doi:10. 1111/j.1469-8137.2012.04198.x

McNickle GG, Deyholos MK, Cahill JF (2015) Nutrient foraging behaviour of four co-occurring perennial grassland plant species alone does not predict behaviour with neighbours. Funct Ecol: n/a-n/a. doi:10.1111/1365-2435.12508

Mommer L, van Ruijven J, de Caluwe H, Smit-Tiekstra AE, Wagemaker CAM, Ouborg NJ, Bogemann GM, van der Weerden GM, Berendse F, de Kroon H (2010) Unveiling below-ground species abundance in a biodiversity experiment: a test of vertical niche differentiation among grassland species. J Ecol 98:1117-1127. doi:10.1111/j.1365-2745. 2010.01702.x

Mommer L, van Ruijven J, Jansen C, van de Steeg HM, de Kroon $\mathrm{H}$ (2012) Interactive effects of nutrient heterogeneity and 
competition: implications for root foraging theory? Funct Ecol 26:66-73. doi:10.1111/j.1365-2435.2011.01916.x

Mommer L, Visser EJW, Ruijven J, Caluwe H, Pierik R, de Kroon $\mathrm{H}$ (2011) Contrasting root behaviour in two grass species: a test of functionality in dynamic heterogeneous conditions. Plant Soil 344:347-360. doi:10.1007/s11104-011-0752-8

Mommer L, Wagemaker CAM, de Kroon H, Ouborg NJ (2008) Unravelling below-ground plant distributions: a real-time polymerase chain reaction method for quantifying species proportions in mixed root samples. Mol Ecol Resour 8: 947-953. doi:10.1111/j.1755-0998.2008.02130.x

Padilla FM, Mommer L, de Caluwe H, Smit-Tiekstra AE, Wagemaker CAM, Ouborg NJ, de Kroon H (2013) Early root overproduction not triggered by nutrients decisive for competitive success belowground. PLoS ONE 8:e55805. doi:10.1371/journal.pone.0055805

R-Core-Team (2014) R: A language and environment for statistical computing. R Foundation for Statistical Computing, Vienna

Rajaniemi TK (2007) Root foraging traits and competitive ability in heterogeneous soils. Oecologia 153:145-152. doi:10. 1007/s00442-007-0706-2

Reich PB (2014) The world-wide "fast-slow' plant economics spectrum: a traits manifesto. J Ecol 102:275-301

Robinson D, Hodge A, Griffiths BS, Fitter AH (1999) Plant root proliferation in nitrogen-rich patches confers competitive advantage. Proc Royal Soc London Ser B-Biol Sci 266:431-435

Roscher C, Schumacher J, Baade J, Wilcke W, Gleixner G, Weisser WW, Schmid B, Schulze ED (2004) The role of biodiversity for element cycling and trophic interactions: an experimental approach in a grassland community. Basic Appl Ecol 5:107-121

Roumet C, Urcelay C, Diaz S (2006) Suites of root traits differ between annual and perennial species growing in the field. New Phytol 170:357-368. doi:10.1111/j.1469-8137.2006. 01667.x

Schroeder-Georgi T, Wirth C, Nadrowski K, Meyer ST, Mommer L, Weigelt A (2016) From pots to plots: hierarchical traitbased prediction of plant performance in a mesic grassland. $\mathrm{J}$ Ecol 104:206-218

Shemesh H, Arbiv A, Gersani M, Ovadia O, Novoplansky A (2010) The Effects of nutrient dynamics on root patch choice. PLoS ONE 5:e10824. doi:10.1371/journal.pone.0010824

Tilman D, Knops J, Wedin D, Reich P, Ritchie M, Siemann E (1997) The influence of functional diversity and composition on ecosystem processes. Science 277:1300-1302

van Ruijven J, Berendse F (2003) Positive effects of plant species diversity on productivity in the absence of legumes. Ecol Lett 6:170-175. doi:10.1046/j.1461-0248.2003.00427.x

van Ruijven J, Berendse F (2005) Diversity-productivity relationships: initial effects, long-term patterns, and underlying mechanisms. Proc Nationl Acad Sci USA 102:695-700. doi: 10.1073 /pnas.0407524102

Violle C, Navas M-L, Vile D, Kazakou E, Fortunel C, Hummel I, Garnier E (2007) Let the concept of trait be functional! Oikos 116:882-892. doi:10.1111/j.2007.0030-1299.15559.x

Wright JP, Naeem S, Hector A, Lehman C, Reich PB, Schmid B, Tilman D (2006) Conventional functional classification schemes underestimate the relationship with ecosystem functioning. Ecol Lett 9:111-120. doi:10.1111/j.1461-0248.2005. 00850.x 